\title{
Universities in the Anglophone centre: Sites of multilingualism ${ }^{1}$
}

\author{
SIÂN PREECE
}

Abstract

This article sets out to examine the increasingly complex linguistic ecology of universities in countries in the Anglophone centre. As universities in these settings have responded to operating in a globalised world, recruitment of students and staff who are multilingual and/ or bi-dialects has significantly increased. However, the diverse and rich linguistic resources that have been brought into the sector are largely ignored or treated as problematic. My intention is to raise linguistic diversity as an issue that needs greater debate and research in these universities, to problematise the monolingual ethos and practices of much of the sector, and to make the case for imagining universities in these settings as sites of multilingualism. This is in the interests of maintaining discourses that represent higher education as in the public good, in which universities have a vital role to play in contributing to the development of pluralistic, multicultural and multilingual societies at national, regional and global levels, in educating "critical citizens of the world" (Giroux 2004: 17), and in promoting an "ethos of personal growth that better represents what humanity might become" (Gibbs et al. 2004: 191).

\section{Introduction}

During the past few decades a mass system of postsecondary education has developed practically across the globe. UNESCO (2009) reports dramatic increases in the student population, with numbers rising from 28.5 million in 1970 to 150.6 million in 2007. A key driver in this expansion has been globalisation, that is the "observable ongoing process of the increasing and ever-more intensive interconnectedness of communications, events, activities and relationships taking place at the local, national or international level" (Block 2006: 3). 
Altbach et al (2009: ii) observe the interconnectedness of globalisation in relation to higher education, commenting on how the sector is being shaped by the increasing integration of national economies, information technology and knowledge networks together with the spread of English and "other forces beyond the control of academic institutions". In universities in Anglophone centre settings, this interconnectedness is also shaping the language or linguistic ecology, which I use in this paper to refer to the cohabitation of an array of languages and dialects in the institution, by fostering the conditions for the growth in recruitment of staff and students from culturally diverse populations around the globe. This is particularly the case in countries that have traditionally been regarded as forming the Anglophone centre, here taken to be the English-dominant nations of the United States, the United Kingdom, Anglophone Canada, Australia and New Zealand. As universities in these countries have expanded, their linguistic ecology has evolved to include the linguistic repertoires of both socalled native speakers of English and bi- and multilingual users of English. The linguistic ecology spans a heterogeneous staff-student population from a range of linguistic minority communities in the Anglophone centre as well as a multitude of English-knowing bi- and multilinguals from around the globe who have been attracted to study and work in Anglophone centre institutions. The linguistic repertoires of this population reflect diverse social, cultural and educational traditions and, in many cases, the "superdiversity" (Vertovec 2006) of urbanised communities around the globe.

However, universities in the Anglophone centre appear to have taken a largely myopic stance to these developments. There is often a mismatch between the monolingual ethos and ideology of institutions and the linguistic diversity of their staff and students. As Kaplan and Baldauf (2009: 43) point out, the attention of educational institutions is commonly "riveted on the national/ official language and perhaps, one or two larger minority languages in the polity". In the case of Anglophone institutions, this riveting of attention has meant a fixation on English and a monoglot ideology (Silverstein 1996), in that universities make efforts to preserve the use of standardised varieties of Anglo-American English and use these prestigious varieties along with disciplinary literacy practices as a "critical tool" (Blommaert 2010: 173) for positioning students and staff as “' 'in' or 'outside' normalcy” (ibid: 165). This has contributed to the linguistic repertoires of bi- and multilingual students being problematised (Ruiz 1984), rather than being treated as multilingual capital (Eversley et al. 2010), and solutions being sought for fixing what are deemed to be language deficiencies. This problem-solution stance adopts an atomistic approach to linguistic diversity, in which the language and literacy practices of the academic community are compartmentalised and taught discretely, separated both from the subject of 
study and from the linguistic repertoires of bi- and multilingual students and staff.

Research into language and identity in higher education in Anglophone centre countries illustrates that this problematising approach to linguistic diversity often results in bi- and multilingual students being positioned as in need of language remediation and being required to take programmes of English language and academic writing (see e.g. Marshall 2010; Martin 2010; Preece 2009, 2010; Simpson and Cooke 2010). This research illustrates ways in which institutional othering of multilingual students often exacerbates feelings of stigmatisation and encourages an oversimplified view of how to address the language needs of a diverse body of students. While there is clearly a role for specialised English language teaching in universities in the Anglophone centre, studies such as the ones above suggest that provision needs to be underpinned by robust institutional policies on linguistic diversity that are sensitive to the complexities of the linguistic ecology of the institution and informed by bi- and multilingual education.

Shohamy (2006: 173) contends that "monolingualism is a myth detached from reality that must be recognized as such by educational systems". This paper aims to contribute to the debunking of this myth in higher education by examining ways in which the linguistic ecology of universities in Anglophone centre countries has become more diverse as a result of globalisation. I find the ecology metaphor generative for this discussion. According to Mühlhäusler and Fill (2001: 3), ecological approaches are concerned with examining "the diversity of inhabitants of an ecology" and finding ways of sustaining this diversity. In this paper, I am concerned with making linguistic diversity visible in Anglophone centre universities and also with increasing its status. Creese and Martin (2003: 1) also observe that ecological perspectives require an "exploration of the relationship of languages to each other and to the society in which these languages exist [including] the geographical, socio-economic and cultural conditions in which the speakers of a given language exist, as well as the wider linguistic environment". Here then, I am concerned with taking a more holistic approach to linguistic diversity than is usually the case in the sector, and treating it as a resource to be maintained and utilised, rather than a problem to be eradicated.

I start by outlining how the global higher education stage has not only facilitated the spread of English in the higher education sector, but also created the conditions for the diversification of the linguistic ecology in universities in the Anglophone centre. Using the UK as an example, I then look at the linguistic ecology at the macro level by examining how the internationalisation agenda, that is the policies and practices that universities implement in response to oper- 
ating in a global environment (Altbach et al 2009), has facilitated the increased movement of students and staff across national boundaries. Following this, I draw on data from my study of language and identity in higher education in the UK (Preece 2009) to illustrate how the access agenda, that is the policies and practices of universities to increase the recruitment and retention of students from underrepresented groups of the domestic population, has affected the linguistic ecology at the micro level of the classroom.

I approach bi- and multilingualism as socially constructed concepts that, as Blackledge and Creese (2010: 6) assert, "have different meanings across different spaces and times". There are various definitions of bi- and multilingualism that reflect different research traditions (see Kemp 2009 for an overview). In this paper, I follow Grosjean's (2010:4) definition of bilinguals as "those who use two or more languages (or dialects) in their everyday lives" to refer to university students who routinely experience their lives in more than one language, and, in most instances, in more than one variety of English. Viewed within the context of universities in the Anglophone centre, this usually involves a prestigious variety of standardised English and a non-prestigious vernacular variety or World English.

\section{The Global Higher Education Stage}

Altbach et al (2009) comment on the ways in which universities are now operating on a global higher education stage. Within a system of global higher education, English has become an exceptionally powerful language. Altbach et al (2009: ii) depict its spread as "unprecedented since Latin dominated the academy in medieval Europe". In a similar vein, Crystal (2004: 37) argues that English has become "the normal medium of instruction in higher education in many countries - including several where the language has no official status". Others take a much more critical stance to the spread of English in the sector. Phillipson (2009: 201) asks whether there is "now an assumption that English is the default medium of higher education, hegemonically projected as being 'normal'?". In Phillipson's view, the rise of English as the dominant language of academia is anything but normal. Rather it has been engineered to serve the wider social, political and economic forces of capitalism, in which universities, particularly those in the Anglophone centre, are increasingly run as corporate concerns in the global marketplace.

Altbach et al (2009) argue that globalisation has increased the tension between the strongest universities, regarded as centres of higher education due to their international reputation for research and excellence, and those on the 
periphery. Institutions regarded as centres are mainly located in the Englishdominant countries of the United States, the United Kingdom, Australia, Canada and New Zealand, and some non-Anglophone industrialised nations, such as France and Germany. According to Altbach et al, the centre-periphery binary has been exacerbated by the ways in which universities are competitively ranked on an international scale. Those institutions at the top of the international ranking generally use English for teaching and research, have significant levels of research funding and offer a wide range of programmes in different disciplines. A look at the world university rankings in 2009 , for example, reveals that out of the top 200 universities in the world, 119 were located in the Anglophone centre, with 71 in the United States, 28 in the United Kingdom, 9 in Australia and 8 in Canada (Times Higher Education 2010). This system of ranking allows those universities at the top to occupy powerful positions on the global higher education stage and to exert significant influence on attitudes to language and literary practices in the sector.

At the same time as globalisation has facilitated the spread of English in higher education, it has also created the conditions for the linguistic ecology in universities in the Anglophone centre to diversify. These conditions have been fostered by the sectors' response to operating in a globalised world, in which policies have been implemented to increase both the numbers of international students and the numbers of domestic students from under-represented groups in the national population. These policies are often referred to as the internationalisation and access (widening participation) agendas respectively. As will be discussed, these agendas have impacted on the linguistic ecology in Anglophone centre universities by facilitating the increase in numbers of bi-, multilingual and/ or bi-dialectal users of English.

\subsection{The internationalisation agenda}

Altbach and Knight (2007) refer to the policies and practices that higher education institutions have set in place to deal with operating in a globalised world as internationalisation and comment on how the implementation of the internationalisation agenda is increasing the mobility of academic staff, students, higher education programmes and institutions across the borders of nation states. They argue that internationalisation is compounding existing centre-periphery inequalities between universities (see also Altbach 2004, Friedman 2005, Odin and Mancias 2004, Phillipson 2009). They point out that while internationalisation creates a "two-way street" (p. 291) between universities in different parts of the world, the process is largely regulated by Anglophone countries, and, to a smaller degree, other major industrialised nations in the EU, such as France and 
Germany. One consequence is that the vast majority of the 2.5 million students who are currently studying overseas have migrated northwards, from countries in Asia, Latin America and Africa, to institutions located in the Anglophone centre; this trend is predicted to continue with the number of international students rising from 2.5 million to around 7 million by 2020 (Altbach et al 2009). Universities in the Anglophone centre largely control this process by regulating admissions to their home institutions and exporting their own programmes of study southwards (via distance learning and off-shore campuses located on the periphery). This state of affairs seems set to continue given the financial rewards for universities and the current crisis in public funding.

The growth in student mobility has impacted on the linguistic ecology in many universities in the Anglophone centre. Taking the UK as an example, in $2008 / 9$, the number of non-UK students in UK higher education institutions rose by 8.2 per cent from 341,790 to 369,970 . Non-UK students represented just over 15 per cent of the total student population and this proportion is expected to rise. Nearly 250,000 students came from countries outside the EU, while just over 100,000 were from EU countries other than the UK (Higher Education Statistics Agency 2010).

Table 1 illustrates the region of domicile for non-UK students in UK universities and demonstrates that there have been increases in student numbers in UK universities from all regions of the world, with the exception of South America and unknown EU countries. Drawing on Kachru's (1992; 1985) model of World Englishes, many of these students are from the Outer and Expanding Circles. For example, in 2008-9 Indian students formed the largest cohort in UK universities

Table 1. Region of domicile of non-UK domicile students 2007/8 and 2008/09 in UK Higher Education Institutions (Higher Education Statistics Agency 2010)

\begin{tabular}{lrrr}
\hline Region of domicile & $\mathbf{2 0 0 7 / 8}$ & $\mathbf{2 0 0 8} / \mathbf{9}$ & \% change \\
\hline Other European Union & 112,150 & 117,660 & $+4.9 \%$ \\
Other Europe & 12,070 & 13,745 & $+13.9 \%$ \\
Africa & 32,295 & 35,180 & $+8.9 \%$ \\
Asia & 137,485 & 150,755 & $+9.6 \%$ \\
Australasia & 2,285 & 2,310 & $+1 \%$ \\
Middle East & 16,690 & 19,325 & $+15.8 \%$ \\
North America & 22,810 & 24,610 & $+7.9 \%$ \\
South America & 4160 & 3590 & $-13.7 \%$ \\
Non-European Union unknown & 1845 & 1800 & $-2.4 \%$ \\
\hline Total non-UK domicile & $\mathbf{3 4 1 , 7 9 0}$ & $\mathbf{3 6 9 , 9 7 0}$ & $+\mathbf{8 . 2 \%}$ \\
\hline
\end{tabular}


from an Outer Circle country, with 34,065 students ${ }^{2}$, whereas Chinese students formed the largest contingent of students from a country in the Expanding Circle with 47,035 students ${ }^{3}$ (Higher Education Statistics Agency 2010).

Students from the Outer Circle in UK universities primarily come from postcolonial settings in which English is generally regarded as a second and/ or official language and is used in a variety of domains. It is highly likely that many will have received some or all of their compulsory education in English-medium schooling. In these settings, indigenous varieties of English have evolved that have de-Anglicised Standard British English by incorporating localised or nativised grammatical, phonological, lexical/ idiomatic and discourse features of their own (Jenkins 2003; Platt et al. 1984). On the other hand, students from countries in the Expanding Circle come from settings in which English is more likely to be perceived of as a foreign language that more exactly conforms to the norms for standardised varieties of Anglo-American English. The use of English in this Circle is often portrayed as restricted to international, rather than intranational, domains.

Given the global spread of English, however, it is questionable whether the differentiation between the roles of English in the Outer and Expanding Circle countries is still fully viable. Over a decade ago, Crystal (1997: 56) commented that the distinction between English as a second and foreign language had 'less contemporary relevance' than previously and that English was in greater use in some places in the Expanding Circle than in some of its traditional bases in the Outer Circle. This point has been widely taken up and there have been a range of studies into the nativisation of English in countries in the Expanding Circle (see e.g. Berns 2005; Bolton 2002; Lowenberg 2002; Rista-Dema 2008; Seargeant 2005; Velez-Rendon 2003). Lowenberg (2002) also points out that students from countries in the Expanding Circle are increasingly studying English in Outer Circle settings where they are learning the norms of Outer Circle standardised varieties of English. He observes how these Outer Circle norms are influencing the development of nativised varieties of English in the Expanding Circle. The debate on World Englishes suggests that students from various countries in the Outer and Expanding Circles may well be bringing a diversity of English dialects into universities in the Anglophone centre as part of their bi- and multilingual linguistic repertoires. As shall be discussed, however, localised varieties of English rarely receive a warm welcome in universities in Anglophone centre settings.

A similar picture of linguistic diversity emerges from the other EU students (i.e. non-UK) within UK institutions. Many of these students can also be regarded as bi- or multilingual users of English. Many come from European countries with two or more official languages either at the state or regional level. 
Similarly to the literature on the Expanding Circle, there is a body of literature documenting the spread of English in member states of the European Union outside the UK and Ireland (see e.g. Berns 1995; Berns 2005; Lowenberg 2002). This literature illustrates how different national and regional varieties of European English are evolving. This suggests that the cohort of European students in UK universities are bringing diverse linguistic repertoires into the sector that include European varieties of English, the 22 official languages of the EU other than English, the indigenous regional and minority European languages and the heritage languages of immigrant communities in Europe.

Finally, it is questionable whether international students in UK universities who are from other Anglophone centre countries are monolingual native speakers of English. Philippson (2009: 202) warns against the "discourse of historical amnesia" that hides the multilingualism and diversity of English-dominant countries, such as the UK and the USA. Given the high levels of cultural and ethnic diversity in settings in the Anglophone centre, it is perfectly possible that a sizeable proportion of students migrating between Anglophone nations are also bi- or multilinguals.

So far, I have discussed how the linguistic ecology in universities in the Anglophone centre has been affected by the increasing recruitment of international students (and EU students in the case of the UK) who are bi- or multilingual users of English. This has been driven by internationalisation policies that are encouraging cross border movement of students, largely from periphery to centre institutions, the majority of which are located in the Anglophone centre. In the following section, I look at the access agenda and discuss how this is affecting the linguistic ecology at the micro level of the classroom.

\subsection{The access agenda}

Allen et al (2005) comment on the attempts that governments in OECD countries have made over the last few decades to improve access to higher education for non-traditional students, that is individuals from underrepresented groups in the domestic population. In the Anglophone centre this agenda has contributed to significant increases in the numbers of domestic students who are multilingual and/ or bi-dialectal users of English of some sort. This body of students is composed of the first, second, third and subsequent generations of minority ethnic groups, the African American and Latino communities in the United States and, to a much more limited degree, the indigenous peoples of Australia, the United States, Canada and New Zealand. These students span a range of different socioeconomic backgrounds, from working class families to those from more socially elite and affluent professional backgrounds. 
While the access agenda has its roots in social justice, globalisation has reframed the debate on access to higher education in neoliberal economic discourses. In this scenario, access to higher education is framed in terms of meeting the needs of industries in the global marketplace by providing a highly educated and skilled workforce. Allen et al (2005: 2) comment that, "[h]igh-modernity or late- or post-modernity means that the industrial heartlands of countries such as the UK and USA have been devastated and, in order to compete in an increasingly tough global market, knowledge and professional skill development are important to the future of our societies". In the UK, this "economizing of universities" (McLean 2006: 45) can be seen by placing universities in the Department for Business, Innovation and Skills (BIS). This Department is composed of ten management groups, ${ }^{4}$ which not only compete for funding but have the collective mission to "[build] a dynamic and competitive UK economy by: creating the conditions for business success; promoting innovation, enterprise and science; and giving everyone the skills and opportunities to succeed. To achieve this it will foster world-class universities and promote an open global economy" (Department for Business Innovation and Skills 2010).

Universities are expected to "[create] a highly-skilled workforce" that is capable of establishing an "enterprise culture where everyone with talent is inspired to turn ideas into successful enterprises" in the free market (ibid). Within the UK, the drive towards skilling the workforce has impacted on the linguistic ecology in universities by encouraging a rise in the numbers of students from non-traditional backgrounds, many of whom are from working class linguistic minority communities. To examine how this is affecting the linguistic ecology at the micro level of the classroom, in the following section I turn to data from my study of language and identity in higher education (Preece 2009).

\section{Multilingual classrooms}

I conducted my study with 93 first-year undergraduate students from a range of linguistic minority groups while they were taking an academic writing programme at a post-1992 university in London. This programme, on which I was a lecturer, had been established to improve the retention of students from widening participation backgrounds. In this case, the majority came from backgrounds that have traditionally been categorised as working class on the basis of occupation. There was also very little history of higher education among the students' parents and elders. Students were enrolled on the programme based on the results of an academic literacy test taken during induction. Most were required to attend the programme rather than opting into it as a free 
choice. The data were gathered over a period of two years and consist of audiorecordings of group work interaction in the classroom and interviews of key participants, field notes from classroom observations and reflections on classroom events, an open-ended questionnaire and information from the student record system.

The linguistic repertoires of the participants in the study included English along with a variety of Creoles and heritage languages in use among members of the Caribbean, South Asian and African communities in London. Some participants were migrants who had been born and educated in Outer Circle settings and had arrived in the UK as young adults. A few came from countries in the Expanding Circle where they had studied English as a foreign language at school. These participants had been in Britain for a short period of time, had come with the intention of studying, following which they were likely to return to their home country. However, most were the children of settled minority ethnic communities in the UK, many of South Asian heritage. Generally these participants had received all or the majority of their compulsory schooling in the British state system and were aged 18-21.

While the institution did not acknowledge the participants' diverse linguistic repertoires in any formal or systematic manner, the participants drew attention to these when given opportunities to do so during the research. An example of this comes in the following extract that was audio-recorded in the classroom, in which four participants, Kavi (aged 21), Sita (aged 19), Tano (aged 23) and Hibba (aged 22) are discussing what languages they use at home and with their friends.

$\mathrm{K}=$ Kavi, $\mathrm{S}=$ Sita, $\mathrm{T}=$ Tano, $\mathrm{H}=\mathrm{Hibba}^{5}$

1. K: I spe- I can speak Tamil/ sort of

2. S: yeah right $<$ laughs $>$

3. K: can you speak any language? I can speak Tamil

4. $\mathrm{T}$ : wha- what language is that?

5. K: that's a Sri Lankan language

6. T: obviously yeah/I can speak my Ghanaian [language so yeah

7. K: [Ghanaian language/ he can speak THREE langua[ges

8. $\mathrm{H}$ :

[I speak FOUR languages

9. K: $\quad$ FOUR languages

10. T: $[$ oh::: <ironic tone>

11. H: [Arabic er Urdu/ Hindi

12. $\mathrm{K}$ : right

13. $\mathrm{H}$ : and Punjabi 
14. K: can you write/ can you/ can you write them?

15. H: yeah

16. $\mathrm{K}$ : yeah you're writing them all?

17. H: yeah

18. K: I can WRITE in Tamil but not fully fluent

19. S: I'm fluent in that [I can/ I can

20. H: [you can read?

21. K: yeah I can read

22. S: I'm [fluent in that

23. T: [proper proper reading?

24. H: like if I gave you a newspaper would you read it from cover to cover?

25. K: yeah/ I can read some articles (xxx) NOT how I read English (classroom data)

The interaction takes on the tone of a sociable sparring contest in which the participants compete with each other for who speaks the most languages and who is the most multiliterate. The interaction opens with Kavi presenting himself as a Tamil speaker, although he mitigates this with the comment 'sort of'(turn 1). Sita's utterance and laughter (turn 2) have a teasing quality. Her ability to tease Kavi about his level of expertise in Tamil comes from their shared heritage as part of the Tamil diaspora in London. Both of their families had sought asylum in the UK as a result of the civil war in Sri Lanka with Kavi arriving in the UK at the age of 11 and Sita being British born.

A series of exchanges then follow between Tano and Kavi (turns 3-7) in which Tano, a mature Ghanaian student who had been the UK for two years at this point, establishes Kavi's heritage culture and represents himself as speaking "my Ghanaian language". His decision not to name the languages in his linguistic repertoire may have been motivated by his perception of his interlocutors' knowledge of Ghana and its linguistic complexities. Nonetheless, Kavi has ascertained something of the linguistic diversity that Tano brings to their group as he announces that Tano speaks three languages (turn 7). The raised volume of 'three' and the tone of this utterance suggest that Tano's multilingualism is to be admired. At this point, Hibba, a British Asian, interrupts (turn 8) in what appears to be a competitive move, to position herself as speaking more languages than Tano, which she then goes on to list (turns 11, 13). The tone of Tano's 'oh' (turn 10) sounds ironic and similarly to Sita's utterance (turn 2) may have been an attempt at playfulness.

This is followed by a series of exchanges (turns 14-25) in which levels of literacy are compared. The interaction is largely controlled by Kavi and Hibba as they weigh up which of them has the greatest level of expertise in their heritage languages. While Hibba claims to be literate in four languages, Kavi concedes 
that he has a greater command of reading in English than in Tamil. While it seems likely that Hibba's greatest expertise is also in English, her claim to have mastery of four languages may have been a strategy for jockeying for position among her peers. Within this group, this appears to have been successful, as her claims went on to earn her the admiration of the group. Throughout the interaction, the participants adopt a multilingual positioning. Their shared experiences as multilinguals appears to facilitate group sociability and construct linguistic diversity as a natural part of daily life.

The portrayal of linguistic diversity as a normal part of everyday life was evident throughout the data. However, a variety of positions were adopted towards this diversity that illustrate the participants' affiliation towards the languages and dialects in their linguistic repertoires within the setting of the academic writing programme and the institution more widely. These positions were fluid, with participants sometimes adopting seemingly contradictory positions. I have discussed elsewhere (Preece 2010) how these positions can be expressed along a continuum of weaker affiliation to heritage languages/stronger affiliation to English and weaker affiliation to English/stronger affiliation to heritage languages. In this paper, I will focus on a number of positions that the students adopted in relation to their linguistic repertoires that appear helpful for considering the needs and identities of heterogeneous groups of multilingual students in universities in the Anglophone centre. These positions are English as L2, separate bilingualism, flexible bilingualism, separate bi-dialectalism and flexible bi-dialectalism.

\subsection{English as $L 2$}

A key position for several of the participants was English as L2, which can be placed towards the weaker affiliation to English/stronger affiliation to heritage languages end of the continuum. As might be expected, migrants commonly adopted this position, particularly if they had arrived in the UK in their late teens and early adulthood. Akinwole illustrates this well. After growing up in Nigeria, where he attended English-medium schools, he migrated to the UK at the age of 19 to join his mother. On arrival, he spent five years working and studying, before he was able to progress into university. In interactions about his linguistic repertoire, Akinwole displayed strong affiliations to Yoruba, depicting this as his 'local language', and much weaker affiliations to English. As Eversley et al (2010) list Yoruba as one of the top-ten languages in London, it is possible that local is a reference to Akinwole's everyday life in areas of London populated by the Yoruba community rather than a reference to his life back home in Nigeria. Akinwole expressed the view that: 
I never feel comfortable speaking in English with my family and friends because I always feel that I am in a formal setting and environment (Akinwole, questionnaire).

Akinwole presents himself as ambivalent to using English at home and with his Yoruba-speaking friends. His association of English with formality suggests that he primarily associates it with institutional settings, perhaps learned during his schooling in Nigeria.

A similar picture emerges from students who can be classified as 1.5 generation. These students migrated to the UK part way through their compulsory schooling and as Marshall (2010: 43) contends, they often inhabit 'liminal spaces, living in two worlds, somewhere between first- and second-generation immigrant'. One student who exemplifies this is Geet. Geet (aged 19) spent his early childhood in Kenya, using Gujarati at home and English and Swahili at school. When he was eight, his family sought asylum in the UK and Geet made the transition from Kenyan schooling into the British education system. After arriving in the UK, Geet also attended a Gujarati complementary school to maintain and improve his oral and written literacy. On comparing Gujarati and English, he claims that:

I have noticed ... when I am ... with my friends, say at work, ... if they speak Gujarati then I will speak Gujarati as well. When I am talking [in] that, I'm more calm and I'm actually more easy going ... When I speak with people just with English, I sometimes stutter ... I might not ... really have the words to say, they are difficult (Geet, Interview 1).

Despite living in the UK from a young age, Geet positions English as his L2. He presents himself as having difficulties with expressing himself in English and claims that spoken interaction that has to be conducted in English only remains as a source of anxiety. Geet goes on to claim that his main motivation for speaking English is to improve his proficiency:

I have Gujarati friends [at university] but they don't usually speak Gujarati that much so ... I'm always speaking English ... so I can improve my English ... I mean ... if I always speak to people [in] English, I'm able to improve my English. But at home ... I have my Gujarati mother tongue language (Geet, Interview 1).

Classroom observations indicated that Geet was often marginalised during group work, particularly when interaction involved witty repartee. As Geet found it almost impossible to participate in the peer group banter of his British-born peers, his silence became the subject for jokes at his expense. As I have discussed (Preece 2006, 2009), adopting the position of English as L2 may have assisted Geet in negotiating social relations with his peers. By adopting $\mathrm{Gu}-$ 
jarati as his mother tongue and English as his second language, Geet was able to position himself as possessing communicative competence in Gujarati and a person worthy of respect among his peers. This position also enabled him to mitigate the problems that he was having with his academic work by allowing him to explain these in relation to being a language learner.

\subsection{Separate bilingualism}

Separate bilingualism (Creese et al. 2008) was a commonly adopted position for the majority of the participants in the study. This can be placed midway along the continuum of weaker affiliation to heritage languages/stronger affiliation to English and stronger affiliation to heritage languages/weaker affiliation to English and gives the impression of equality and balance between languages. Separate bilingualism indicates a view of languages as discrete and bounded entities that are used in different domains and need to be kept apart. This separation has been described in various ways, such as the two solitudes (Cummins 2005) and parallel monolingualism (Heller 1999, 2006). Drawing on Gravelle (1996: 11), Creese and Blackledge (2010: 105) observe how separate bilingualism "represents a view of the multilingual/bilingual student/teacher as "two monolinguals in one body"'. An example of this comes in the following extract of interview data with Saba (aged 18), a British Pakistani, who uses English, Urdu and Punjabi, in which we are discussing the associations that she makes with these languages. Saba is typical of the British born participants in that she had received very little sustained schooling in her heritage languages.

To tell you the truth the language that you speak at home ... obviously there is more tradition comes into it, culture comes into it, religion comes into it, which is good 'cause obviously you need to like ... keep a hold of your tradition and your culture and stuff like that, which is good, so your language Punjabi, Urdu comes into that. English ... obviously you are in the country everyone speaks it you have to know it ... the outside world is more based on ... English ... and I think that our language our mother tongue is for like home and your family and keeping the traditions, stuff like that (Saba, Interview 1).

In this interaction, Saba makes a clear distinction between the languages in her linguistic repertoire, demarcating Punjabi and Urdu for the domain of her family and English for use in the "outside world". She constructs Punjabi and Urdu as maintaining the cultural and religious traditions of her heritage culture as well as interactions among family members. The private realm is constructed as excluding English in opposition to the public domain, which is portrayed as more or less English only. This example is typical of the ways in which many 
of the participants adopted a separate bilingual positioning. This positioning bounded heritage languages to the domestic and private space of the family and heritage community and English to the public domains of life beyond the ancestral community.

\subsection{Flexible bilingualism}

Another position marking the midway point on the continuum is flexible bilingualism (Creese et al. 2008). Unlike separate bilingualism, in which efforts are made to keep languages apart, flexible bilingualism indicates the use of codeswitching, in which "the speaker makes a complete shift to another language for a word, phrase, or sentence" (Grosjean 2010: 51-2). This was characterised in the data as mixing of English and heritage language(s). This position is illustrated in the interview interaction below with Ling (aged 20), a British Chinese student, in which we are discussing her use of code switching.

Ling: Cantonese is mainly for like my parents and my grandma but um when I am communicating with my brothers and sisters we kind of mix up Cantonese and English.

SP: Can you think of any situations when you would really mix up the Cantonese with the English when you are talking to your friends? What particular subjects do you think you talk about?

Ling: Um anything really 'cause it is like when I am talking to you it is like you wouldn't know Chinese so I'll have to stick to English but when you know someone that is Chinese and they know English as well you kind of mix it up just naturally it's not like when you change a subject (Ling, Interview 1).

Ling's linguistic repertoire encompassed English, Cantonese, Vietnamese, British Sign Language and Mandarin. In this interaction, she differentiates her use of flexible bilingualism from separate bilingualism. In interactions with others whose linguistic repertoire encompasses Cantonese and English, such as her siblings and friends, Ling adopts the position of a flexible bilingual by reporting that she routinely juxtaposes Cantonese and English regardless of the topic of conversation. However, when her interlocutor's linguistic repertoire differs (her elders and $\mathrm{me}$ ), she is obliged to use "one language at a time" and "one language only" (Li and Wu 2009).

This resonates with a variety of studies, such as Creese et al (2006: 38) and Li Wei and $\mathrm{Wu}(2009)$ whose study of complementary schools in the UK found that second generation minority ethnic teenagers valued being able to code-switch between their heritage languages and English. One use of code-switching was to construct a distinctive identity from first generation migrants. As Creese et 
al (2006: 38) comment, flexible bilingualism is a way in which British born bilinguals can differentiate themselves from newly arrived migrants and adopt positions as sophisticated young people in relation to the migrant freshie who is not proficient in the linguistic practices of the peer group. Unlike separate bilingualism, flexible bilingualism blurs the boundaries of the private and public worlds that second generation minority ethnic students inhabit, suggesting that they routinely use English in the home context alongside heritage languages and that heritage languages are used alongside English outside the home.

Grosjean (2010) observes that code-switching is commonplace among bilinguals who share the same languages. He identifies a variety of reasons for codeswitching, including the attractiveness of one language compared to another for expressing particular ideas, imitation of others and emphasis of social role. Grosjean also comments on the ways in which code-switching is often viewed negatively as creating "an unpleasant mixture of languages, produced by people who are careless about the way they speak" (p. 52). This perception was prevalent among the participants in my study who frequently associated code-switching with linguistic deficit. This view is typified by Awino (aged 32), a Kenyan migrant who had been living in the UK for ten years at the time of the research:

When I speak Swahili with my friends I find I break it with English sometimes/ speak English as well as Swahili/ some kind of mixes/ which is not really good (Awino, classroom data).

This utterance comes from interaction between Awino, Biba (aged 22) and Leela (aged 19), a British Moroccan and British Asian respectively, about the languages that they use at home and with friends. Despite portraying code switching as a habitual practice, they also conformed to ideological norms that associate it with deficit and semilingualism. These negative connotations often came to the fore when intergenerational relations were the subject of discussion:

$\mathrm{S}=$ Seema, $\mathrm{M}=$ Maya

1. S: I speak English [mixed like (.) I don't know

2. M: [talked with $((\mathrm{xx}))$ / and I was like $($.$) half and half=$

3. S: =half yeah: (1) but most of the time it's in English okay/ now they've like/ changed (1)

4. M: they know it

5. S: they think it's bad though/ you know how parents are

6. M: it's very bad we don't know the language $<$ laughs $>$

In the extract above two British Asians of Gujarati heritage, Seema (aged 19) and Maya (aged 19), are discussing their parents' negative response to their habitual 
use of code switching. The face-threatening nature of this exchange, in which they are sharing the experience of not only disagreeing with their parents but also acting against their wishes, is suggested through the covert references to their parents and elders in the ambiguous use of 'they' (turns 3-5). The use of an impersonal pronoun in combination with the pauses in turn 3 is suggestive of shared experiences of family relationships. Maya's utterance (turn 6) may be enacting a parental disapproving voice with the accompanying laughter signalling that this is a subject for humour. However, the laughter may also mask anxieties about not fulfilling parental expectations and of not conforming to dominant discourses on bilingualism that assume that languages must be kept separate (see e.g. Blackledge and Creese 2010; Cummins 2005; Heller 2006).

\subsection{Separate and flexible bi-dialectalism}

The notion of separation and flexibility is also helpful for reflecting on the participants' relationship with English. As mentioned, all were bi-dialectal users of English. The majority were habitual users of a vernacular variety, in particular London English (Harris 2006), while some were users of World Englishes. They routinely adopted bi-dialectal positions that were articulated through a posh/slang binary to differentiate between the prestigious variety of Standard English that they were required to use in higher education and the non-prestigious varieties of English with which they strongly identified.

In interactions about their use of posh and slang, the participants adopted the positions of separate and flexible bi-dialectalism. These mirror separate and flexible bilingualism in that the first involves the separation of standard and vernacular varieties of English while the latter involves their juxtaposition. An example of separate bi-dialectalism is illustrated in the following interaction between Awino, Biba and Leela, in which they are discussing their attempts at making friends with their undergraduate peers.

1. L: when we came 'ere/ I mean/ if I saw a posh person I actually spoke posh with them/ but if I saw somebody who was happy with their slang/ I spoke slang with them/ and I think that's how you socialise with them/

2. A: yeah/

3. B: it's how you adapt to different people [that's what adapting is about/

4. A: [yeah/ you've got to adapt/ yeah/

5. L: yeah/

6. B: adapting to different people an' their cultures y'know/ an' their backgrounds (classroom data). 
In the interaction, Biba, Leela and Awino co-construct boundaries between posh English and slang, which enables them to categorise the people that they are encountering in university into people like themselves, who are "happy with their slang" and posh others. They portray themselves as keeping posh and slang apart by using posh with one group of potential friends and slang with another. The regular reference to posh and slang in reference to the student body suggests that the participants have constructed an understanding based on shared experiences of social class norms for appearance, language and behaviour. It also suggests that the participants paid attention to the "soundscape" (Harris 2006), accommodating to the accents and conversational styles of their fellow peers as a way of fitting in and making friends. It may be that separate bi-dialectalism enables working class students to navigate alien social terrain that includes many more people from middle class and professional backgrounds than they have previously encountered during schooling. In this instance, this positioning also facilitates a narrative of success in establishing new social relationships in higher education.

Similarly to flexible bilingualism, the participants also adopted the position of flexible bi-dialectalism. An example of this comes from interview data with Tahir (aged 22), a British Pakistani, in which we are discussing how he makes sense of the academic work in his discipline:

There's five of us so we ... all sit down and we're trying to [explain] ... the good thing is ... whoever knows in that circle how to do it, he explains to all of us and because we all know each other well, know slang and stuff, we'd explain it in a way we will understand ... whilst if the teacher explains I might not get [it] ... So I'd explain it in my terms to make sure they understand it ... showing the thinking, how I know how to do it (Tahir, Interview 2).

In this interaction, Tahir reports that he has formed a study group with his peers. This is represented as a "circle", suggesting collaboration and cooperative learning. Flexible bi-dialectalism is used as a tool for constructing understanding of disciplinary knowledge by juxtaposing "slang and stuff" with the language of the academic community. This position also appears to be empowering in that it enables Tahir to speak from a position of expertise in which he can scaffold the intellectual development of his male peers. This is in sharp contrast to the institutional positioning that he occupies as a remedial English language user on the English language programme.

While vernacular English has little legitimacy within the institution, the participants' representations suggest that far from being a hindrance, they found vernacular English a valuable resource for establishing peer group relations and constructing a bridge into their academic work. This resonates with Rampton's 
(2006: 316) “vernacularisation of school knowledge", in which adolescents use posh and Cockney stylisations as a way of mediating school work and getting down to the task at hand. Given the closeness in background and educational experience of Rampton's participants to those in my study, it seems likely that this strategy has been transferred from London schools into higher education.

\section{Discussion}

The statistics for non-UK students in UK institutions and data from research conducted on the academic writing programme illustrate some of the ways in which the linguistic ecology of universities in the Anglophone centre has become more complex. However, despite the linguistic diversity in their midst, universities in Anglophone settings still seem to be operating with the assumption that their students are monolingual native speakers of English who 'naturally' use a standardised variety of Anglo-American English and who enter university with considerable expertise in the literacy practices common in Anglo-American academic traditions. Although universities in the Anglophone centre claim to celebrate the cultural diversity of the student body, there is often less than a warm welcome for the linguistic diversity that accompanies cultural and social diversification. While ethnic monitoring in Anglophone settings is commonplace, there appears to be little systematic documentation of the linguistic repertories of students and staff. There is also a lack of institutional wide language policies that could inform curricula design and delivery. Curricula still largely adopt a monolingual stance that encourages uncritical use of "one language only" (OLON) ( $\mathrm{Li}$ and $\mathrm{Wu} 2009)$ and by extension one dialect only (ODON) for most of the time. Universities in the Anglophone centre have not kept pace with the changing student demographic and need to devise institutional language policies that take pluricentric, rather than monocentric, perspectives to linguistic diversity. These could then be used to inform curricula design, delivery and assessment that are appropriate at the local level and more sensitive to the needs and identities of a linguistically diverse student population.

In order to support the development of language policies there is a need for further research into linguistic diversity in Anglophone centre universities. Quantitative studies that map the linguistic repertoires of the staff-student population at institutional level would be helpful in developing the bigger picture, in raising awareness of linguistic diversity in the sector and for examining claims that multilingualism is the norm for significant numbers of staff and/ or students in these settings. Further qualitative work exploring identity and pedagogical issues is also required as multilingual students do not form a homogeneous 
group and are likely to exhibit differing levels of expertise and affiliation to the languages in their repertoires. They are also likely to have differing investment in the academic language and literacy practices of the Anglophone centre. For international students who have incurred very sizeable costs of studying in an Anglophone country, they may well be invested in the standardised English of the Anglophone centre, viewing this as carrying status and prestige. This may fuel resistance to using L1 in the university context. For domestic students, however, and for some from postcolonial settings, they may experience ambivalent feelings about the academic linguistic and literacy practices to which they are expected to conform. There are also emerging patterns from research about the ways in which multilingual students both conform to and resist the dominant norms for compartmentalising the languages and dialects in their linguistic repertoires. It would be helpful to draw on the research into separate and flexible bilingualism in complementary schooling in the HE sector and to extend the notion of separation and flexibility to varieties of English. This would enable further examination of the salience of separate and flexible bilingualism and bi-dialectalism within the context of higher education.

Kachru's model could provide a starting point for recognising linguistic diversity and hybridity of English use. While this model clearly has its limitations for describing the current situation in relation to English in different parts of the world, it serves the purpose of highlighting the "pluralism, heterogeneity, and diversity of English world-wide" (Berns, 1995: 10). It can be used to draw attention to the diverse linguistic repertoires of students in universities in the Anglophone centre and provide a way of critiquing attitudes in these universities to the linguistic diversity in their midst. Within this context, it also helps to re-position the remedial English user as an "English-knowing bilingual" (Pakir 1999) or "bilingual user of English" (McKay 2002) and to call attention to Lowenberg's (2002: 433) plea to find ways of differentiating between "deficiencies in the second language acquisition of English ... [and] varietal differences in the speakers' usage resulting from their having previously learned and used ... non-native normative features" [italics in original]. At present, there is little differentiation between the two as is illustrated in Simpson and Cooke's (2010: 70) study that illustrates how the sector's negative reaction to non-prestigious varieties of English of migrant students can contribute not only to these students experiencing downwards educational trajectories, but also to their longer terms prospects of educational success being damaged. This resonates with Blommaert's (2010) argument that the linguistic resources of those coming from the periphery are evaluated against a "mainstream" that reflects the "national order" of the Anglophone centre (p. 173). Describing the asylum application of Joseph, a Rwandan refugee in the UK, Blommaert critiques the 
ways in which linguistic resources of those from the periphery not only "[lose] weight and value during the journey [to the UK]", but are also used by those in authority in the Anglophone centre to create arguments for doing things to people, such as refusing asylum applications or enforcing immersion education.

Altbach et al (2009: viii) comment that one of the biggest challenges facing higher education in the global world is making opportunities available on an equitable basis. As they argue "if current trends of internationalization continue, the distribution of the world's wealth and talent will be further skewed". In the very unequal world in which we live and work, it is my contention that universities in the Anglophone centre need to exercise particular care not to increase the gap between the haves and have nots through language practices that privilege elite groups, whether these be monolingual or bilingual users of English, who already hold a disproportionate share of power and wealth. The call to imagine universities as multilingual spaces is intended as a way of valuing the knowledge and linguistic resources of bi- and multilingual students from a wide range of backgrounds, of creating spaces for other knowledge and perspectives to be critically evaluated and of finding ways of using linguistic diversity as a bridge into academic studies and a resource in the design, delivery and assessment of the curriculum.

In conclusion, the mass expansion of tertiary education has resulted in an increasingly complex linguistic ecology in universities in the Anglophone centre. The linguistic ecology has been shaped by policies that universities have put into place to deal with globalisation, in particular the internationalisation and access agendas. While these universities are sites of multilingualism, this is barely recognised. When language appears on the agenda, it is generally with a "problem" label that frequently results in bi- and multilingual students being labelled as in need of remedial English tuition. It is my contention that we need to recognise linguistic diversity in the sector and consider ways of treating it as an asset. The first step in this direction is to imagine universities in Anglophone settings as multilingual spaces and to acknowledge that multilingualism needs to be given space beyond "the heads of the students or of ... teaching ... staff who are bi- or multilingual" (Phillipson 2009: 210).

\section{Notes}

1. This paper is based on a presentation at the 2010 Bloomsbury Round Table

2. representing a rise of $31.5 \%$ on $2007 / 8$ figures

3. representing a rise of $3.7 \%$ on $2007 / 8$ figures 
4. Universities and Skills are one management group in BIS. This group is situated with nine other management groups, namely: Business; Economic and Policy Analysis; Fair Markets; Finance and Commercial; Innovation and Enterprise (including the Better Regulation Executive); Legal, People and Communications; Science and Research; Shareholder Executive and UK Trade \& Investment.

5. All participant names are pseudonyms.

\section{References}

Allen, Liz, Lucy Solomon, John Storan and Liz Thomas. 2005. International comparators of widening participation in higher educaction - policy and practice: Higher education in the USA, student fees, financial aid and access. Action on Access.

Altbach, Philip, Liz Reisberg and Laura Rumbley. 2009. Trends in global higher education: tracking an academic revolution. Executive Summary. A Report prepared for the UNESCO 2009 World Conference on Higher Education. Paris: United Nations Educational, Scientific and Cultural Organisation.

Berns, Margie. 1995. English in the European Union. English Today 4. 3-11.

Berns, Margie. 2005. Expanding on the expanding circle: where do WE go from here? World Englishes 24. 85-93.

Blackledge, Adrian and Angela Creese. 2010. Multilingualism: a critical perspective. London: Continuum.

Block, David. 2006. Multilingual identities in a global city: London stories. London: Palgrave Macmillan.

Blommaert, Jan. 2010. The Sociolinguistics of globalization. Cambridge: Cambridge University Press.

Bolton, Kingsley. 2002. Chinese Englishes: from Canton jargon to global English. Special Issue of World Englishes 21. 181-200.

Creese, Angela, Arvind Bhatt, Nirmala Bhojani and Peter Martin. 2006. Multicultural, heritage and learner identities in complementary schools. Language and Education 20. 23-43.

Creese, Angela and Adrian Blackledge. 2010. Translanguaging in the bilingual classroom: a pedagogy for learning and teaching? The Modern Language Journal 9. 10315.

Creese, Angela and Peter Martin. 2003. Multilingual classroom ecologies: inter-relationships, interactions and ideologies. In Creese, Angela and Peter Martin (eds.) Multilingual classroom ecologies: inter-relationships, interactions and ideologies Clevedon: Multilingual Matters. 1-7.

Creese, Angela, Barac Taskin, Arvind Bhatt, Adrian Blackledge, Shahela Hamid, Li Wei, Vally Lytra, Peter Martin, Chao-Jung Wu and Dilek Yagcioglu-Ali. 2008. Investigating multilingualism in complementary schools in four communities. Birmingham: University of Birmingham. 
Crystal, David. 1997. English as a global language. Cambridge: Cambridge University Press.

Crystal, David. 2004. The past, present and future of World English. In Gardt, Andreas and Bernd Huppauf (eds.) Globalization and the future of German Berlin: Mouton de Gruyter. 27-45.

Cummins, Jim. 2005. A proposal for action: strategies for recognizing heritage language competence as a learning resource within the mainstream classroom. Modern Language Journal 89. 585-92.

Department for Business Innovation and Skills. 2010. About BIS. http://www.bis.gov.uk/ about (accessed 10 December 2010).

Eversley, John, Dina Mehmedbegovic, Antony Sanderson, Teresa Tinsley, Michelle vonAhn and Richard Wiggins. 2010. Language capital: mapping the languages of London's school children London: CILT.

Gibbs, Paul, Panayiotis Angelides and Pavlos Michaelides. 2004. Preliminary thoughts on a praxis of higher education teaching. Teaching in Higher Education 9. 183-94.

Giroux, Henry. 2004. Betraying the intellectual traditional: public intellectuals and the crisis of youth. In Phipps, Alison and Manuela Guilherme (eds.) Critical pedagogy: political approaches to language and intercultural communication Clevedon: Multilingual Matters. 7-21.

Gravelle, M. 1996. Supporting bilingual learners in schools. Stoke-on-Trent: Trentham Books.

Grosjean, Francois. 2010. Bilingual: life and reality. Cambridge Massachusetts: Harvard University Press.

Harris, Roxy. 2006. New ethnicities and language use. Basingstoke: Palgrave Macmillan. Heller, Monica. 1999. Linguistic minorities and modernity. London: Continuum.

Heller, Monica. 2006. Linguistic minorities and modernity. 2nd ed. London: Continuum. Higher Education Statistics Agency (2010). Statistics - students and qualifiers at UK HE institutions.

Jenkins, Jennifer. 2003. World Englishes: a resource book for students. London: Routledge.

Kachru, B. 1992. Models for non-native Englishes. In Kachru, B (ed.) The Other tongue. Englishes across cultures 2nd. Urbana: University of Illinois Press.

Kachru, Braj B. 1985. Standards, codification and sociolinguistic realism: the English language in the outer circle. In Quirk, Randolf and H. G. Widdowson (eds.) English in the world: teaching and learning the language and literatures. Cambridge: Cambridge University Press. 11-30.

Kaplan, Robert and Richard Baldauf. 2009. An Ecological perspective on language planning. In Creese, Angela, Peter Martin and Nancy Hornberger (eds.) Encyclopedia of Language and Education, vol. 9 2nd. New York: Springer.

Kemp, Charlotte. 2009. Defining multilingualism. In Aronin, Larissa and Britta Hufeisen (eds.) The exploration of multilingualism: development of research on L3, multilingualism, and multiple language acquisition Amsterdam: John Benjamins. 11-26. Li, Wei and Chao-Jung Wu. 2009. Polite Chinese children revisited: creativity and the 
use of codeswitching in the Chinese complementary school classroom. International Journal of Bilingual Education and Bilingualism 12: 193-211.

Li, Wei and Chao-Jung Wu. 2009. Polite Chinese children revisited: creativity and the use of codeswitching in the Chinese complementary school classroom. International Journal of Bilingual Education and Bilingualism 12: 193-211.

Lowenberg, Peter H. 2002. Assessing English proficiency in the Expanding Circle. World Englishes 21. 431-5.

Marshall, Steve. 2010. Re-becoming ESL: multilingual university students and a deficit identity. Language and Education 24. 41-56.

Martin, Peter. 2010. 'They have lost their identity but not gained a British one': nontraditional multilingual students in higher education in the United Kingdom'. Language and Education 24. 9-20.

McKay, Sandra. 2002. Teaching English as an international language: rethinking goals and approaches. Oxford: Oxford University Press.

McLean, Monica. 2006. Pegagogy and the university: critical theory and practice. London: Continuum.

Mühlhäusler, Peter and Alwin Fill (eds.). 2001. The Ecolinguistics reader: language, ecology and environment. London: Continuum.

Pakir, Anne. 1999. Connecting with English in the context of internationalism. TESOL Quarterly 33. 103-12.

Phillipson, Robert. 2009. Linguistic imperalism continued. Hyderabad: Orient Blackswan.

Platt, John Talbot, Heidi Weber and Ho Mian Lian. 1984. The New Englishes. London: Routledge.

Preece, Siân (2006). British Asian undergraduate students in London. In Block, David, Multilingual Identities in a Global City: London Stories. London: Palgrave Macmillan. 171-99.

Preece, Siân. 2009. Posh talk: language and identity in higher education. London: Palgrave Macmillan.

Preece, Siân. 2010. Multilingual identities in higher education: negotiating the 'mother tongue', 'posh' and 'slang'. Language and Education 24: 21-40.

Rista-Dema, Mimoza. 2008. Verb-subject word order in Albanian English. World Englishes 27. 419-33.

Ruiz, Richard. 1984. Orientations in language planning. NABE: The Journal for the National Association for Bilingual Education .12-34.

Seargeant, Philip. 2005. Globalisation and reconfigured English in Japan. World Englishes 24. 309-20.

Shohamy, E. 2006. Imagined multilingual schools: How come we don't deliver? In Garcia, O., Tove Skutnabb-Kangas and M. Torres-Guzman (eds.) Imagining multilingual schools. Languages in education and globalization Clevedon: Multilingual Matters. 171-83. 
Silverstein, Michael. 1996. Monoglot 'standard' in America: standardization and metaphors of linguistic hegemony. In Brenneis, D and R Macaulay (eds.) The Matrix of language: contemporary linguistic anthropology Boulder: Westview Press. 284-306.

Simpson, James and Melanie Cooke. 2010. Movement and loss: progression in tertiary education for migrant students. Language and Education 24. 57-74.

Times Higher Education (2010). Times Higher Education-QS World University Rankings 2009: Top 200 world universities.

UNESCO Institute for Statistics (2009). Trends in tertiary education: Sub-Sarahan Africa. UIS Fact Sheet, July 2009, No. 01.

Velez-Rendon, Gloria. 2003. English in Colombia: a sociolingustic profile. Special Issue of World Englishes 2. 185-98.

Vertovec, Steven. 2006. The emergence of super-diversity in Britain. http://www.compas. ox.ac.uk/fileadmin/files/pdfs/Steven\%20Vertovec\%20WP0625.pdf(accessed 09 November 2010).

Siân Preece is a Lecturer in TESOL education at the Institute of Education, University of London. She is interested in applied linguistics in educational settings and her research interests include linguistic and cultural diversity, language learning and widening participation and language and gender. She is the author of Posh Talk: Language and Identity in Higher Education and has published several articles on multilingual and gender identities. s.preece@ioe.ac.uk 
Brought to you by | UCL - University College London Authenticated

Download Date | 3/8/16 11:25 AM 